\title{
KARAKTERISTIK TANAH TERDAMPAK DAN TIDAK TERDAMPAK LIKUIFAKSI BERDASARKAN UJI SWEDISH WEIGHT SOUNDING PADA KELURAHAN PETOBO
}

\author{
Hendra Setiawan ${ }^{1}$, Sigit Kurniawan ${ }^{1}$ \\ ${ }^{1}$ Jurusan Teknik sipil, Fakultas Teknik, Universitas Tadulako \\ Jl Soekarno Hatta Km. 9, Palu, Sulawesi Tengah, 94118 \\ Corresponding author:hendra3909@gmail.com
}

\begin{abstract}
Abstrak
Gempa bumi 28 September 2018 yang mengguncang Kota Palu dan sekitarnya dengan kekuatan 7,4 $\mathrm{M}_{\mathrm{W}}$ memicu terjadinya likuifaksi di beberapa lokasi, salah satunya adalah di sebagian wilayah Petobo. Likuifaksi yang terjadi di daerah ini mengakibatkan pergeseran tanah yang masif sehingga menimbulkan kerugian material dan korban jiwa.Penelitian ini bertujuan untuk mengetahui karakteristik tanah terdampak dan tidak terdampak likuifaksi berdasarkan uji Swedish Weight Sounding pada Kelurahan Petobo. Pengujian lapangan yang dilakukan yaitu dengan alat uji Swedish Weight Sounding. Adapun pengujian laboratorium yang dilakukan meliputi pengujian Analisa saringan dan batas-batas Atterberg. Hasil yang diperoleh dari penelitian ini meliputi hasil pengujian laboratorium dan pengujian di lapangan. Untuk hasil pengujian di laboratorium, jenis tanah yang didapat pada lokasi tersebut yaitu CL dan CL-ML. Sedangkan untuk hasil pengujian lapangan, nilai Nsw di daerah tidak terdampak berkisar antara 0-250 $\mathrm{n} / \mathrm{m}$, nilai Nsw untuk daerah terdampak berkisar antara $8-72 \mathrm{n} / \mathrm{m}$, nilai qa di daerah tidak terdampak berkisar antara $0-230 \mathrm{kN} / \mathrm{m}^{2}$, nilai qa untuk daerah terdampak berkisar antara 0 $167,6 \mathrm{kN} / \mathrm{m}^{2}$, nilai qu untuk daerah tidak terdampak berkisar antara $30-180 \mathrm{kN} / \mathrm{m}^{2}$, dan nilai qu untuk daerah terdampak berkisar antara $30-133,2 \mathrm{kN} / \mathrm{m}^{2}$.
\end{abstract}

Kata Kunci : Tidak terdampak likuifaksi, terdampak likuifaksi, Swedish Weight Sounding, Likuifaksi

\begin{abstract}
The 2018 Sulawesi Earthquake that shook the city of Palu and its surroundings with a strength of 7.4 MW triggered liquefaction in several locations, one of which was in a part of Petobo. Liquefaction that occurred in this region resulted in massive ground movement resulting in material losses and casualties. This study aims to determine the characteristics of affected and non-affected liquefaction land based on the Swedish Weight Sounding test in Petobo Village. Field testing was carried out using the Swedish Weight Sounding test equipment. The laboratory tests carried out include sieve analysis and Atterberg limits.The results obtained from this study include the results of laboratory testing and field testing. For test results in the laboratory, types obtained at these locations are CL and CL-ML soil types. As for the field test results, the Nsw value in the unaffected area ranges from 0-250 $\mathrm{n} / \mathrm{m}$, the $N s w$ value for the affected area ranges from 8-72 $\mathrm{n} / \mathrm{m}$, the qa value in the unaffected area ranges from 0-230 $\mathrm{kN}$ $/ \mathrm{m}^{2}$, the qa value for the affected area ranges from 0-167.6 $\mathrm{kN} / \mathrm{m}^{2}$, the qu value for the unaffected area ranges from $30-180 \mathrm{kN} / \mathrm{m}^{2}$, and the qu value for the affected area ranges from $30-133.2 \mathrm{kN} / \mathrm{m}^{2}$.
\end{abstract}

Keywords: non-affected, affected, Swedish Weight Sounding, Liquefaction 


\section{PENDAHULUAN}

Fenomena likuifaksi merupakan fenomena ketika kekuatan dan kekakuan tanah berkurang dikarenakan gempa atau pergerakan tanah lainnya. Hal ini merupakan suatu proses atau kejadian berubahnya sifat tanah dari keadaan padat menjadi keadaan cair, yang disebabkan oleh beban siklik pada waktu terjadi getaran gempa sehingga tekanan air pori meningkat mendekati atau melampaui tegangan vertikal. Daerah zona lemah dan ditambah fenomena likuifaksi menyebabkan pondasi rumah dan bangunan tinggi mengalami penurunan, retakan pada badan jalan dan tanggul sungai maupun perpindahan lateral dan longsoran. Hasil penelitian Tohari, dkk (2011) menunjukkan bahwa fenomena likuifaksi terjadi karena keberadaan lapisan pasir jenuh air dengan kepadatan yang bervariasi dari lepas hingga medium hingga kedalaman $10 \mathrm{~m}$.

Pada tanggal 28 september 2018 bencana gempa bumi di Sulawesi tengah yang berkekuatan 7,4 $\mathrm{M}_{\mathrm{w}}$ ini mengakibatkan beberapa daerah mengalami bencana seperti Tsunami di Pinggiran laut Donggala dan Palu, Kebakaran di Kelurahan Balaroa Kecamatan Palu barat Kota Palu, dan bencana Likuifaksi terjadi di daerah Palu dan Sigi.

Bencana likuifaksi yang terjadi di Kabupaten Sigi berada di Desa Sibalaya, Desa Jonooge, Desa Pombewe, dan Desa Rego, sedangkan yang di Kota Palu terjadi di Kelurahan Balaroa dan Petobo. Dari beberapa lokasi tersebut penyusun memilih desa Petobo untuk melakukan suatu penelitian mengenai karakteristik tanah di daerah tersebut.

Tujuan dari penelitian ini adalah untuk mengetahui karakteristik tanah terdampak dan tidak terdampak berdasarkan uji Swedish Weight Sounding pada Kelurahan Petobo.

\section{TINJAUAN PUSTAKA}

\section{Gempa Bumi}

Zen dalam Hatmoko (2016), mendefinisikan gempa sebagai gerakan tiba-tiba atau sederetan gerakan tiba-tiba dari tanah dan batuan yang bersifat transient dan berasal dari suatu daerah terbatas yang kemungkinan menyebar ke segala arah karena dirambatkan oleh medium yang ada (lapisan bumi). Gempa bumi menurut Katili dalam Hatmoko (2016), didefinisikan sebagai suatu sentakan asli yang terjadi di bumi, bersumber dari dalam bumi yang kemudian merambat di permukaan.

\section{Likuifaksi}

Likuifaksi adalah fenomena hilangnya kekuatan tanah akibat getaran gempa bumi. Likuifaksi terjadi pada tanah yang berpasir lepas dan jenuh air (Tohari dkk, 2015). Lapisan tanah dengan campuran pasir merupakan lapisan yang memiliki porositas baik, sehingga memungkinkan lapisan ini menyimpan dan mengalirkan air. Lapisan yang memiliki porositas yang baik memicu penyerapan air dalam lapisan yang menyebabkan lapisan tersebut jenuh air.

Seiring naiknya tekanan air yang diakibatkan oleh guncangan gempa, maka tegangan efektif menjadi berkurang. Modulus pasir menurun bersamaan dengan turunnya tegangan efektif. Hal ini mengakibatkan tanah pasir menjadi melunak (mencair). Akibatnya tanah tidak mampu menopang beban di atasnya dan menyebabkan amblasnya bangunan, miring ataupun longsor (Muntohar, 2010).

Ada 3 faktor utama penyebab likuifaksi yaitu tanah berbutir kasar, posisi muka air tanah yang tidak jauh dari permukaan, dan gempa bumi.

\section{Definisi Tanah}

Tanah dalam pengertian Teknik secara umum, didefinisikan sebagai material yang terdiri dari agregat (butiran) material-material padat yang tidak bersementasi (terikat secara kimia) satu sama lainnya dan terdiri dari bahan-bahan organik melapuk (yang berpartikel padat) disertai dengan cairan dan gas yang mengisi 
Karakteristik tanah terdampak dan tidak terdampak likuifaksi berdasarkan uji Swedish Weight Sounding pada kelurahan Petobo

ruang-ruang kosong (pori) diantara partikelpartikel padat tersebut.

\section{Analisa Saringan}

Analisa saringan adalah cara mekanis untuk menganalisis distribusi ukuran butiran tanah berbutir kasar (yaitu butiran yang tertahan saringan No. 200), dan rumus yang digunakan adalah :

$$
\% \text { tertahan }=\frac{\text { Wtertahan }}{\text { Wtotal }} \times 100 \%
$$

Jenis tanah yang rentan terhadap likuifaksi adalah tanah pasir lepas sampai medium yang jenuh. Tsuchida (1970) meringkas hasil analisis saringan pada sejumlah tanah yang diketahui telah terlikuifaksi dan yang tidak terlikuifaksi selama gempa bumi. Kurva ukuran butir yang memisahkan tanah yang dapat terlikuifaksi dan tidak ditunjukkan pada Gambar 1

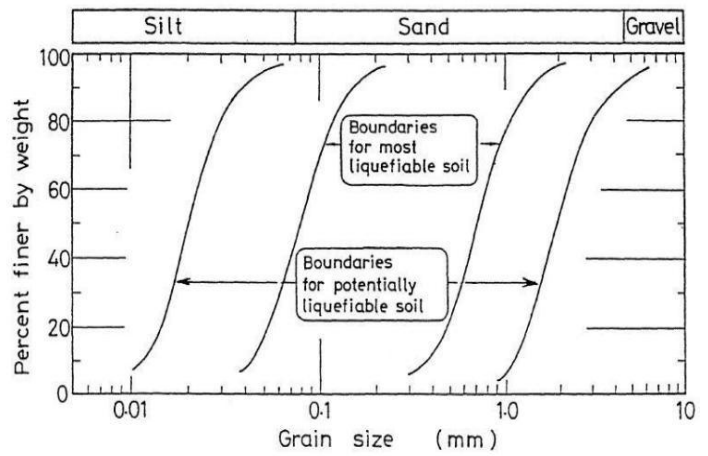

Gambar 1. Kurva Distribusi Ukuran Butir Tanah yang Rentan Terhadap Likuifaksi (Tsuchida, 1970)

\section{Swedish Weight Sounding}

Swedish Weight Sounding menurut JIS A 1221, adalah alat untuk mengukur ketahanan penetrasi statis tanah asli dan untuk menilai kekerasan tanah atau komposisi lapisan tanah. Alat ini sangat sederhana serta memiliki kemampuan penetrasi yang relativ baik dan digunakan untuk survei tanah dengan kedalaman $10 \mathrm{~m}$.

Uji Swedish Weight Sounding ini biasa juga digunakan untuk mendapatkan profil tanah kontinu dan juga untuk mengidentifikasi urutan lapisan tanah. Hal ini juga berguna dalam membedakan profil tanah tidak kontinyu yang disebabkan oleh likuifaksi dan tanah longsor. Karena penggunaan alat yang relatif mudah, uji Swedish Weight Sounding sering dilakukan untuk penyelidikan tanah di daerah yang hancur oleh gempa bumi. Gambar 2 menunjukkan alat uji Swedish Weight Sounding.

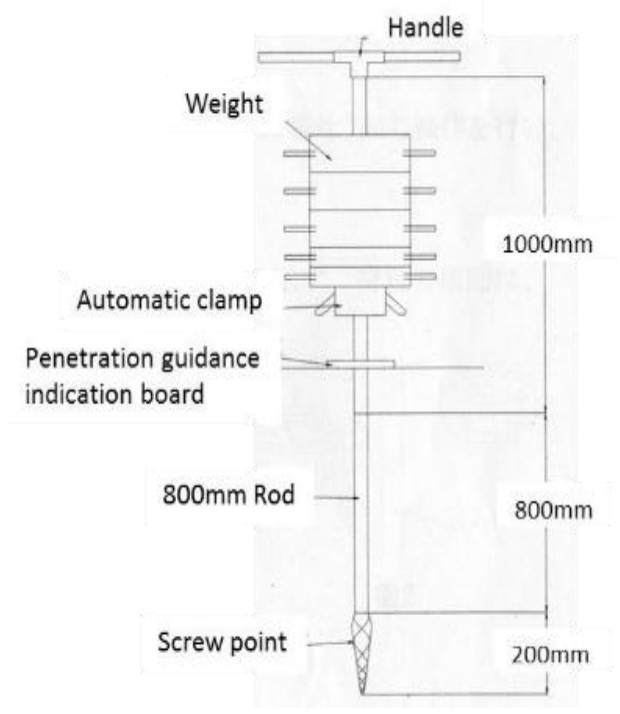

Gambar 2. Alat Swedish Weight Sounding

\section{METODE PENELITIAN}

\section{Lokasi Penelitian}

Lokasi penelitian terletak di Kelurahan Petobo, Kecamatan Palu Selatan, Kota Palu, Provinsi Sulawesi Tengah. Lokasi penelitian dapat dilihat pada Gambar 3.

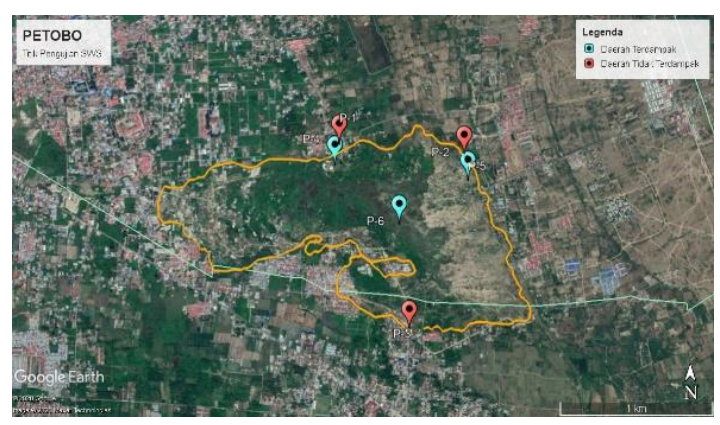

Gambar 3. Lokasi Penelitian

\section{HASIL DAN PEMBAHASAN}




\section{Analisa Saringan}

Pengujian Analisa saringan dilakukan dengan terlebih dahulu mengambil sampel tanah kering sebanyak 600 gram lalu di oven selama 24 jam. Sampel dicuci pada saringan 200. Sampel yang tertahan saringan 200 kemudian di oven lagi selama 24 jam, untuk kemudian diuji Analisa saringan. Pengambilan sampel berada di lokasi tidak terdampak dan terdampak likuifaksi. Hasil analisa saringan dapat dilihat pada Gambar 4 dan Gambar 5

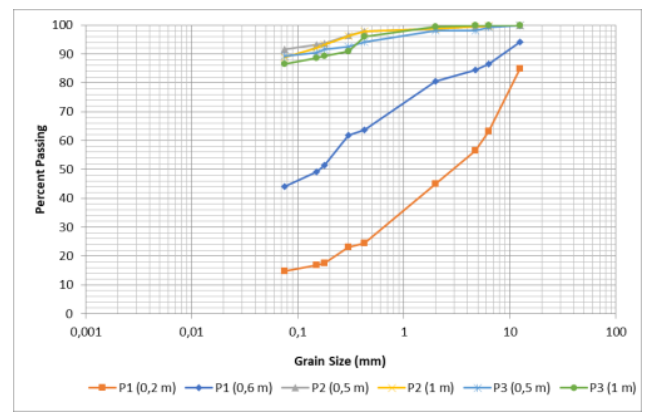

Gambar 4. Gradasi untuk masing-masing titik pengambilan sampel pada daerah tidak terdampak likuifaksi

Gambar 4 menunjukkan bahwa dari hasil analisa saringang dari 6 sampel pada area tidak terdampak likuifaksi, 2 sampel pada titik P1 dikategorikan sebagai tanah berbutir kasar karena kurang dari 50\% yang lolos saringan no. 200. Sampel pada titik P2 dan P3 dikategorikan sebagai tanah berbutir halus karena lebih dari $50 \%$ yang lolos saringan no. 200

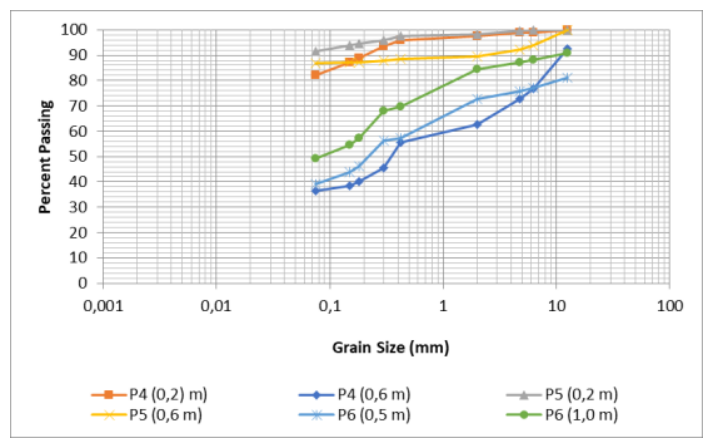

Gambar 5. Gradasi untuk masing-masing titik pengambilan sampel pada daerah terdampak likuifaksi
Hasil analisa saringan pada Gambar 5 menunjukkan dari 6 sampel pada area terdampak likuifaksi, sampel di titik P4 pada kedalaman 0,5 $\mathrm{m}-0,7 \mathrm{~m}$ dan 2 sampel pada titik P6 dikategorikan sebagai tanah berbutir kasar karena kurang dari 50\% yang lolos saringan no. 200. Sedangkan sampel pada titik P4 di kedalaman 0,1 m-0,3 $\mathrm{m}$ dan 2 sampel pada titik P5 dikategorikan sebagai tanah berbutir halus karena lebih dari 50\% yang lolos saringan no. 200

\section{Batas-Batas Atterberg}

Pengujian Batas-Batas Atterberg dilakukan untuk tanah yang lebih dari 50\% lolos saringan no. 200. Hasil pengujian dapat dilihat pada Tabel 1.

Tabel 1. Hasil Pengujian Batas-batas Atterberg

\begin{tabular}{|c|c|c|c|c|c|c|}
\hline Titik & $\begin{array}{c}\text { Kedalaman } \\
\text { Sampel (m) } \\
\text { (m) }\end{array}$ & $\begin{array}{c}\text { Persentase } \\
\text { lolos } \\
\text { Saringan } \\
\text { No. } 4 \\
(\%) \\
\end{array}$ & $\begin{array}{c}\text { Persentase } \\
\text { lolos } \\
\text { Saringan } \\
\text { No. 200 } \\
(\%) \\
\end{array}$ & $\begin{array}{l}\text { LL } \\
(\%)\end{array}$ & $\begin{array}{c}\text { PI } \\
(\%)\end{array}$ & $\begin{array}{c}\text { Klasifikasi Tanah } \\
\text { (Unified) }\end{array}$ \\
\hline \multirow{2}{*}{$\mathrm{P} 2$} & $0,40-0,60$ & 99,500 & 91,700 & 27,72 & 11,76 & $\mathrm{CL}$ \\
\hline & $0,90-1,10$ & 99,500 & 88,800 & 29,24 & 9,87 & CL \\
\hline \multirow{2}{*}{ P3 } & $0,40-0,60$ & 98,200 & 89,300 & 44,11 & 14,06 & $\mathrm{CL}$ \\
\hline & $0,90-1,10$ & 99,800 & 86,500 & 37,47 & 22,18 & CL \\
\hline P4 & $0,10-0,30$ & 98,800 & 82,000 & 33,75 & 17,79 & CL \\
\hline \multirow{2}{*}{ P5 } & $0,40-0,60$ & 99,700 & 91,700 & 25,65 & 13,12 & CL \\
\hline & $0,90-1,10$ & 92,300 & 86,800 & 21,29 & 6,00 & CL - ML \\
\hline
\end{tabular}

Tabel 1 memperlihatkan bahwa sampel di titik P5 pada kedalaman 0,9 m - 1,1 m merupakan tanah lempung anorganik - lanau anorganik (CL-ML). Sampel lainnya termasuk dalam kategori tanah lempung anorganik (CL).

\section{Swedish Weight Sounding}

Pengujian dilakukan di 3 titik yang berada pada area terdampak likuifaksi dan 3 titik berada pada area tidak terdampak likuifaksi menggunakan 1 set alat Swedish Weight Sounding. Titik pengujian dapat dilihat pada Gambar 6. 
Karakteristik tanah terdampak dan tidak terdampak likuifaksi berdasarkan uji Swedish Weight Sounding pada kelurahan Petobo

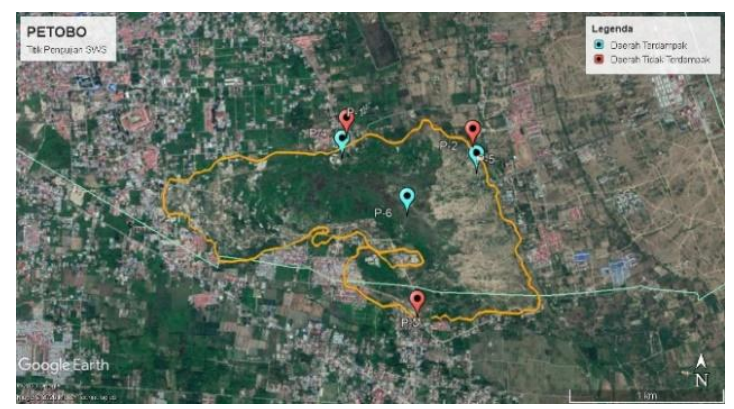

Gambar 6. Titik Pengujian alat Swedish Weight Sounding

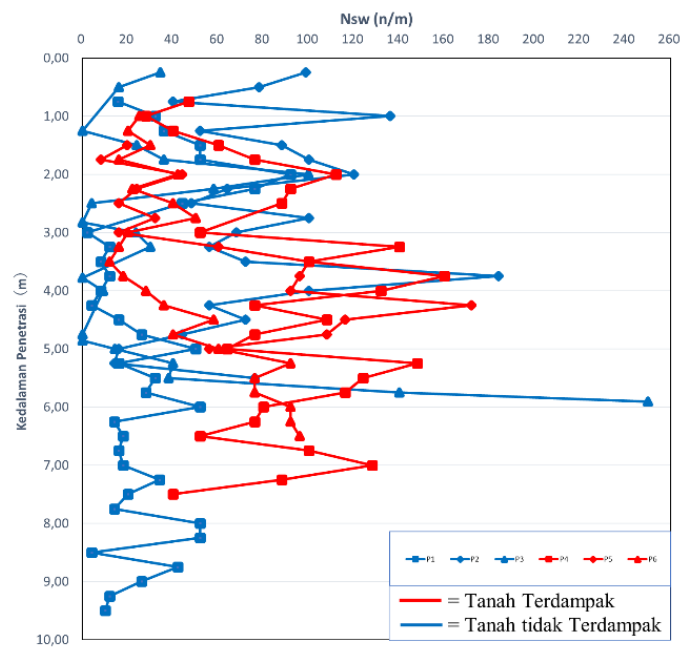

Gambar 7. Grafik Hubungan antara Nsw dan Kedalaman Penetrasi

Gambar 7. memperlihatkan bahwa nilai Nsw tertinggi pada kedalaman antara 0-2 meter berada di kedalaman 1 meter pada tanah tidak terdampak dengan nilai Nsw $136 \mathrm{n} / \mathrm{m}$. Pada kedalaman antara 2-4 meter berada di kedalaman 3,75 meter pada tanah tidak terdampak dengan nilai Nsw 184 n/m. Sedangkan pada kedalaman antara 4-6 meter berada di kedalaman 5,91 meter pada tanah tidak terdampak dengan nilai Nsw $250 \mathrm{n} / \mathrm{m}$.

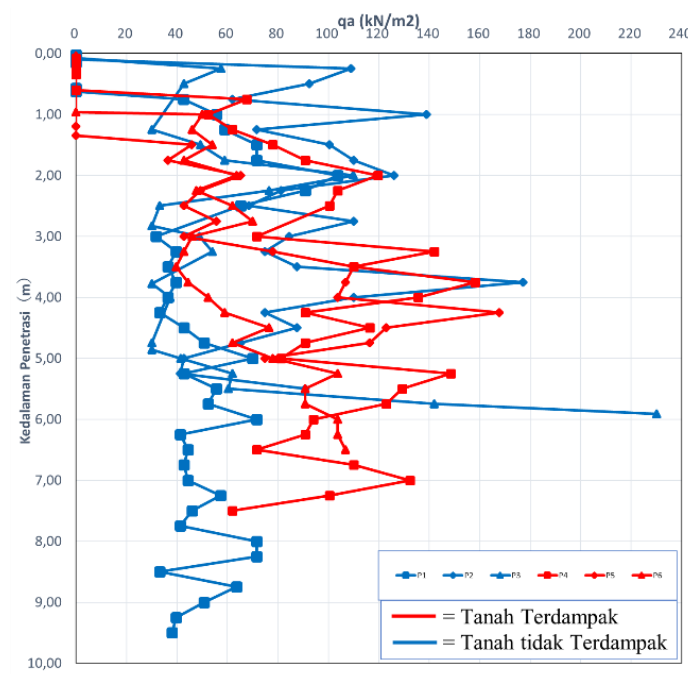

Gambar 8. Grafik Hubungan antara qa dan Kedalaman Penetrasi

Gambar 8. memperlihatkan bahwa nilai qa tertinggi pada kedalaman antara 0-2 meter berada di kedalaman 1 meter pada tanah tidak terdampak dengan nilai qa $138,8 \mathrm{kN} / \mathrm{m}^{2}$, pada kedalaman antara 2-4 meter berada di kedalaman 3,75 meter pada tanah tidak terdampak dengan nilai qa $177,2 \mathrm{kN} / \mathrm{m}^{2}$, dan pada kedalaman antara 4-6 meter berada di kedalaman 5,91 meter pada tanah tidak terdampak dengan nilai qa $230 \mathrm{kN} / \mathrm{m}^{2}$.

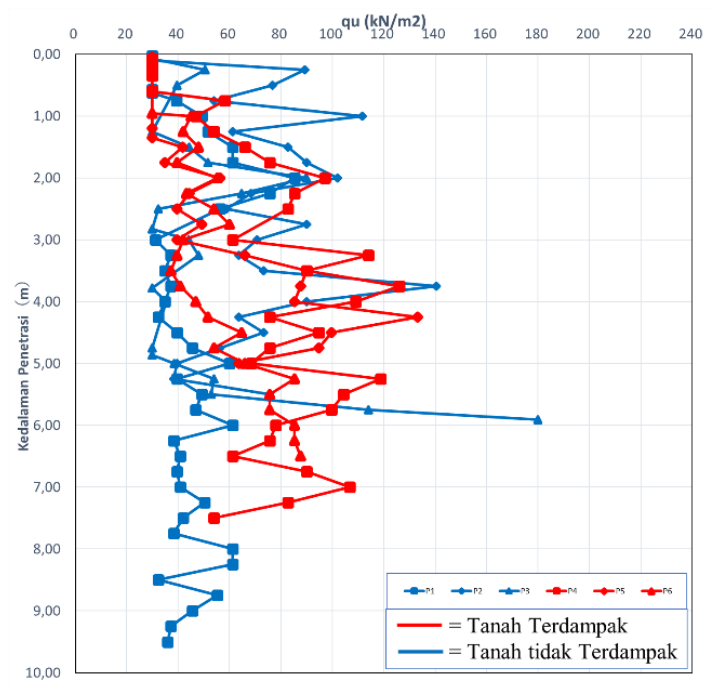

Gambar 9. Grafik Hubungan antara qu dan Kedalaman Penetrasi

Gambar 9 memperlihatkan bahwa nilai qu tertinggi pada kedalaman antara 0-2 meter berada di kedalaman 1 meter pada tanah tidak terdampak dengan nilai qu $111,6 \mathrm{kN} / \mathrm{m}^{2}$, pada 
kedalaman antara 2-4 meter berada di kedalaman 3,75 meter pada tanah tidak terdampak dengan nilai qu $140,4 \mathrm{kN} / \mathrm{m}^{2}$, dan pada kedalaman antara 4-6 meter berada di kedalaman 5,91 meter pada tanah tidak terdampak dengan nilai qu $180 \mathrm{kN} / \mathrm{m}^{2}$.

\section{Pembahasan}

Hasil pengujian Analisa saringan, dapat dihubungkan dengan kurva potensi likuifaksi berdasarkan ukuran butiran seperti pada Gambar 10 :

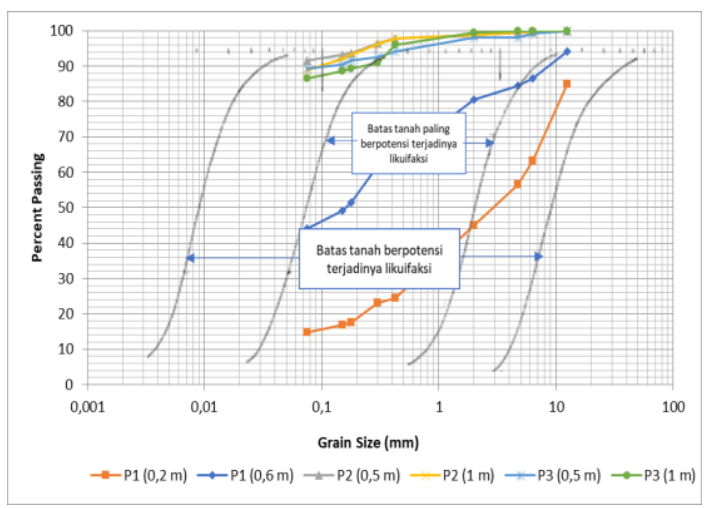

\section{Gambar10 Grafik potensi likuifaksi berdasarkan ukuran butiran di daerah tidak terdampak likuifaksi}

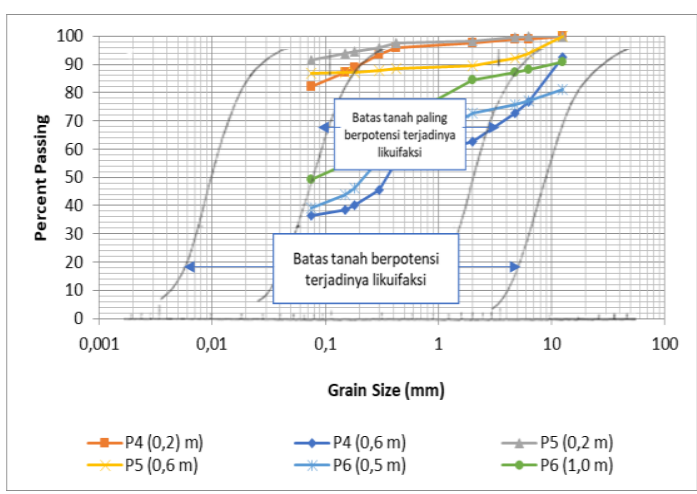

Gambar 11. Grafik potensi likuifaksi berdasarkan ukuran butiran di daerah terdampak likuifaksi

Gambar 10. dan Gambar 11. memperlihatkan bahwa tanah di daerah tidak terdampak maupun terdampak likuifaksi termasuk tanah yang paling berpotensi likuifaksi. Hal ini mungkin terjadi dikarenakan sampel yang digunakan uji adalah sampel yang lokasi pengambilannya tidak jauh dari batas daerah tidak terdampak dan terdampak likuifaksi.

Hasil pengujian Batas-batas Atterberg, menunjukkan bahwa jenis tanah yang di uji yaitu jenis lempung anorganik(CL) dan lempung anorganik-lanau anorganik (CL-ML).

Kesimpulan dari hasil pengujian Swedish Weight Sounding, menunjukan bahwa tidak ada tanah terdampak yang nilai Nsw nya lebih dari $180 \mathrm{n} / \mathrm{m}$. Tanah yang memiliki nilai Nsw antara $120-180 \mathrm{n} / \mathrm{m}$ dapat terjadi likuifaksi, walaupun memiliki kemungkinan yang lebih kecil bila dibandingkan tanah yang memiliki nilai Nsw di bawah $120 \mathrm{n} / \mathrm{m}$. Tidak ada tanah terdampak yang nilai qa nya lebih dari 170 $\mathrm{kN} / \mathrm{m}^{2}$. Tanah yang memiliki nilai qu antara $120-170 \mathrm{kN} / \mathrm{m}^{2}$ dapat terjadi likuifaksi, walaupun memiliki kemungkinan yang lebih kecil bila dibandingkan tanah yang memiliki nilai qa di bawah $120 \mathrm{kN} / \mathrm{m}^{2}$. Tidak ada tanah terdampak yang nilai qu nya lebih dari 140 $\mathrm{kN} / \mathrm{m}^{2}$, sedangkan untuk tanah yang memiliki nilai qu antara $100-140 \mathrm{kN} / \mathrm{m}^{2}$ dapat terjadi likuifaksi, walaupun memiliki kemungkinan yang lebih kecil bila dibandingkan tanah yang memiliki nilai qu di bawah $100 \mathrm{kN} / \mathrm{m}^{2}$.

\section{PENUTUP}

\section{Kesimpulan}

Berdasarkan hasil pengujian lapangan dan laboratorium yang dilakukan terhadap beberapa sampel tanah, dapat disimpulkan sebagai berikut:

Hasil pengujian Analisa Saringan dan Batasbatas Atterberg serta mengikuti pengklasifikasian tanah berdasarkan USCS, memperlihatkan berbagai jenis tanah yaitu lempung anorganik (CL) yang tanah lolos saringan no. 200 lebih dari 50\%, memiliki nilai $\mathrm{LL} \leq 50 \%$, nilai PI lebih dari 7\% ; lempung anorganik - lanau anorganik (CL-ML) yang tanah lolos saringan no. 200 lebih dari 50\%, memiliki nilai $\mathrm{LL} \leq 50 \%$, nilai PI berada di antara 4\% - 7\%; dan pasir berlanau - pasir 
Karakteristik tanah terdampak dan tidak terdampak likuifaksi berdasarkan uji Swedish Weight Sounding pada kelurahan Petobo

berlempung (SM - SC) yang jumlah tanah tertahan saringan no. 200 lebih dari 50\%, dan lebih dari $50 \%$ jumlah tanah yang lolos saringan no. 4.

Daerah yang tidak terdampak likuifaksi, memiliki 3 parameter yang didapatkan dari pengujian lapangan yaitu nilai Nsw yang berkisar antara $0-250 \mathrm{n} / \mathrm{m}$, nilai qa yang berkisar antara $0-230 \mathrm{kN} / \mathrm{m}^{2}$, dan nilai qu yang berkisar antara $30-180 \mathrm{kN} / \mathrm{m}^{2}$.

Daerah yang terdampak likuifaksi, juga memiliki 3 parameter yang didapatkan dari pengujian lapangan yaitu nilai Nsw yang berkisar antara $8-172 \mathrm{n} / \mathrm{m}$, nilai qa yang berkisar antara $0-167,6 \mathrm{kN} / \mathrm{m}^{2}$, dan nilai qu yang berkisar antara $30-133,2 \mathrm{kN} / \mathrm{m}^{2}$.

Hasil pengujian dengan Swedish Weight Sounding menunjukkan bahwa parameter kekuatan tanah (Nsw, qa, dan qu) pada daerah tidak terdampak likuifaksi lebih tinggi daripada daerah terdampak likuifaksi. Hal itu bisa terjadi dikarenakan kondisi tanah pada daerah terdampak seperti pada bagian midside merupakan timbunan dari tanah pada bagian upside yang tergerus. Adapun beberapa hasil pengujian lapangan menunjukkan adanya variasi pada hasil yang sedikit berbeda, tetapi sejauh ini masih berkesinambungan antara parameter yang satu dan lainnya pada bagian tertentu di lokasi penelitian.

\section{Saran}

Pengembangan penelitian ini dengan menggunakan alat Swedish Weight Sounding, perlu dilakukan dengan alat dengan jumlah titik yang lebih banyak, mengingat luas wilayah daerah petobo yang terdampak cukup besar, sehingga hasil yang didapatkan akan lebih mewakili kondisi asli.

Pelatihan singkat penggunaan alat perlu dilakukan sebelum melakukan pengujian di lapangan.

\section{DAFTAR PUSTAKA}

Hatmoko, J.T. (2016). Dinamika Tanah dan Liquefaction, Cahaya Atma Pustaka. Yogyakarta.

Muntohar, A. S. (2010). Mikrozonasi Potensi Likuifaksi dan Penurunan Tanah Akibat Gempa Bumi. Penelitian Dosen. Yogyakarta: UMY.

Tohari, A., Sugianti, K., Soebowo, E. (2011). Liquefaction potential at Padang City: a comparison of predicted and observed liquefaction during the 2009 Padang earthquake. Jurnal Riset dan Pertambangan, Puslit Geoteknologi-LIPI, 21 (1), pp.7-18

Tohari, A. Sugianti, K. Syahbana, A. J. (2015) .Kerentanan Likuifaksi Wilayah Kota Banda Aceh Berdasarkan Metode Uji Penetrasi Konus. Pusat Penelitian Geoteknologi LIPI.

Tsuchida, H., (1970), Prediction and Countermeasure against Liquefaction in Sand Deposits, Proceeding of Abstract of the Seminar of the Port and Harbour Research Institute, Ministry of Transport, Yokosuka, Japan. 